\title{
Birthweight and gestational age centiles in South Indian newborns
}

\author{
*Grace Lalana Christopher ${ }^{1}$ \\ Sri Lanka Journal of Child Health, 2019; 48(2): 140-145
}

\begin{abstract}
Background: India has recently gone through a vast technological and economic revolution which has influenced all sections of society. The study was undertaken to determine any changes in the pattern of intrauterine growth in South Indian babies over three decades compared with national and international studies.
\end{abstract}

Objectives: To construct new 2015-2017 centile charts for birthweight in babies born from 28 to 42 gestational weeks in the metropolitan city of Bangalore, South India compared with an earlier South Indian centile chart constructed in 1983 at Christian Medical College and Hospital (CMCH), Vellore, India and other national and international studies.

Design, setting and method: This is a retrospective study of two cohorts. The first cohort consisted of 4,426 consecutive live births from January to December 1983, at $\mathrm{CMCH}$, a tertiary referral hospital in South India. The second cohort consisted of 2,708 consecutive live births from January 2015 to May 2017 at Shifaa Hospital, a multispecialty centre, in the metropolitan city of Bangalore, South India, about $300 \mathrm{~km}$ from $\mathrm{CMCH}$. The chief outcome measure was birthweight centiles according to gestational age. The two cohorts of singleton live births were analysed to determine the mean birth weights, gestation and centile growth patterns. Data were obtained from labour room records.

Results: Among a total of 4,426 live births during 1983 , the mean birthweight was $2881 \mathrm{~g}$ and among 2,708 live births during 2015-2017, the mean birth weight was $2873 \mathrm{~g}$, a difference of $8 \mathrm{~g}$. The mean gestation was 38.8 weeks in the former and 38.2 weeks in the latter study respectively. The centile

\footnotetext{
${ }^{1}$ Consultant Paediatrician, Grace Specialist Clinic, $1^{\text {st }}$ Floor, Maruthi Complex, Ramamurthynagar Main Road, Bangalore, South India

*Correspondence: gracelalana@gmail.com

(iD https://orcid.org/0000-0001-5510-1579

(Received on 31 May 2018: Accepted after revision on 20 July 2018)

The authors declare that there are no conflicts of interest Personal funding was used for the project.
}

growth curves among the two cohorts revealed almost similar percentile weight distribution except for preterm 31-36 weeks gestation, where birthweights in the 2015-2017 cohort were 200-300g higher compared to the 1983 cohort. However, the $90^{\text {th }}$ centile curve, at term $38-40$ weeks revealed an increase of 200-300g weight gain in 1983 cohort which thereafter plateaued, with $300 \mathrm{~g}$ weight gain at 40-41 weeks in the 2015-2017 cohort. Comparison was also made with both national and international centile intrauterine growth curves.

Conclusions: The 2015-2017 centile charts for birthweight in babies born from 28 to 42 gestational weeks in the metropolitan city of Bangalore, South India had almost similar growth curves and mean birthweights compared to the 1983 South Indian centile chart indicating an inherent genetic predisposition for the small Indian baby. The updated centiles for births during 2015-2017 provide a more valid tool to assess South Indian fetal growth.

DOI: http://dx.doi.org/10.4038/sljch.v48i2.8708

(Key words: Asian birthweight, gestational age, centiles, SGA, LGA, AGA)

\section{Introduction}

Birth weight is an indicator of antenatal well-being, postnatal complications and survival ${ }^{1,2}$. Although birth weight is a standard, cut-offs like $1500 \mathrm{~g}$ or $2500 \mathrm{~g}$ do not differentiate the roles of growth and maturity unlike birth weight for gestational age $\mathrm{ag}^{3,4}$. Birthweight percentiles demonstrating birthweight distribution at each gestational age help clinicians to identify babies who require increased monitoring. Population specific updated growth charts are useful for the categorisation of babies as small for gestational age (SGA), large for gestational age (LGA) or appropriate for gestational age (AGA).

\section{Objectives}

This is a retrospective study. The study was carried out with the aim of:

- $\quad$ Estimation of birth weights and gestational ages in two cohorts of babies born in 1983 and 2015-2017 in South India.

- To obtain a standard birth weight and gestational age centiles reference range for South Indian babies. 
- $\quad$ Comparison of $10^{\text {th }}, 25^{\text {th }}, 50^{\text {th }}, 75^{\text {th }}$, and $90^{\text {th }}$ centile growth charts over three decades to determine inherent or genetic factors at play rather than environmental factors, as newborn birth weights are expected to increase due to technological advances and economic reforms over the decades.

- Comparison of the above mentioned statistics with available national and international studies.

\section{Method}

This is a retrospective study of two cohorts. The first cohort consisted of 4,426 consecutive live births from January to December 1983, at Christian Medical College and Hospital (CMCH) Vellore, a tertiary referral hospital in South India. The second cohort consisted of 2,708 consecutive live births from January 2015 to May 2017 at Shifaa Hospital, a multispecialty centre, in the metropolitan city of Bangalore, South India, about $300 \mathrm{~km}$ from $\mathrm{CMCH}$, both centres catering to almost similar middle and lower socioeconomic populations.

Data were obtained from the labour room register at $\mathrm{CMCH}$, Vellore for 4426 live births in 1983, and from the labour room register at Shifaa Hospital, Bangalore for 2078 live births in 2015-2017. All consecutive live births delivered between 28 to 42 weeks of gestation were considered. In the 1983 study, gestation was estimated based on a reliable menstrual history, early antenatal clinical examination, and in around $60 \%$, using sonographic fetal biometry. In the 2015-2017 study, crown-rump length (CRL) measurement by ultrasound examination was undertaken in all women within 18-20 weeks to establish fetal age when menstrual dates were unknown or in pregnancy with discrepancy greater than \pm 7 days. If CRL and menstrual dates agreed to within the normal range of error ( \pm 7 days), then the last menstrual period was used to establish fetal age. Gestational age is recorded as completed gestational weeks.

Birth weights were measured within an hour of birth on a Braun electronic weighing scale to the closest $50 \mathrm{~g}$ in the 1983 study and on a digital weighing machine accurate up to $\pm 10 \mathrm{~g}$ in the 2015-2017 study. The data were entered using EPIINFO software in the 1983 study. In the 2015-2017 study, data were entered into EPIDATA entry software, 3.1.2701.2008 and data analysis was done using STATA version 13.1. The actual birth weight centiles were used to construct the charts rather than smoothed centiles. The extremely low birthweights below 28 weeks gestation were excluded being few in number and outliers. Centile charts were constructed for birthweight in infants 28 to 42 weeks' gestation.

\section{Results}

There were 4,426 consecutive live births during the twelve months from January to December 1983 at $\mathrm{CMCH}$, Vellore and 2,708 consecutive live births during twenty nine months from January 2015 to May 2017 at Shifaa Hospital, Bangalore. The mean birthweights were $2881 \mathrm{~g}$ during the 1983 study and $2873 \mathrm{~g}$ during the 2015-2017 study, a difference of $8 \mathrm{~g}$. The centile growth charts were constructed using actual birthweights. However similar mean birthweights were noted with a difference of only $8 \mathrm{~g}$ in the 2015-2017 study, with changes in maternal factors over past three decades, with $16 \%(\mathrm{n}=553)$ aged 20-24 years a difference of $24 \%$. Thus $70.9 \%$ $(n=2471)$ among 3481 mothers with known maternal age in the 1983 cohort were older than 24 years compared to $52.2 \%(n=1351)$ among 2583 mothers with known maternal age in 2015-2017 cohort. The distribution of mothers according to age in years is seen in Figure 1.

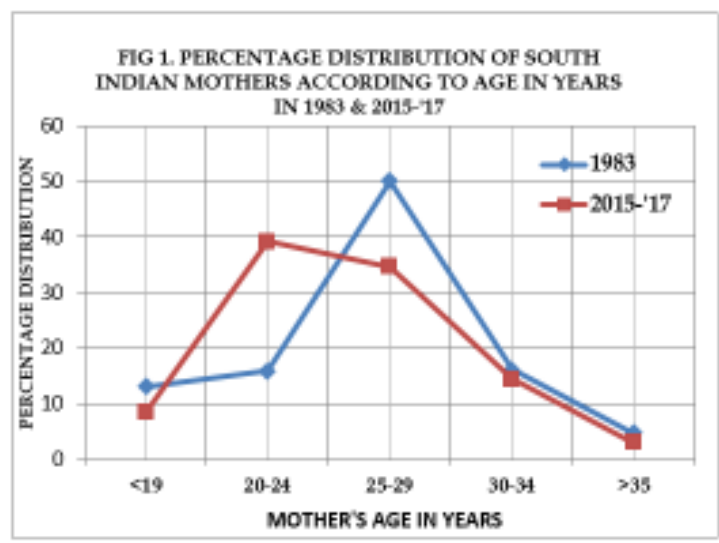

Although $34.1 \% \quad(n=1519) \quad$ were primigravidae among a total 4426 births in the 1983 cohort, this reduced to $22.4 \% \quad(n=992)$ for second gravida mothers but increased to $25.5 \%(\mathrm{n}=1134)$ for third gravida mothers. In contrast, $32.7 \%(n=876)$ were primigravida mothers among a total 2673 mothers with known parity in the 2015-2017 cohort with a progressive decline in numbers by $5-10 \%$ for subsequent pregnancies. Thus $71 \%$ of mothers were aged 25 years and above, with $43.3 \%$ having three or more pregnancies, in the earlier 1983 cohort compared to $52.3 \%(\mathrm{n}=1351)$ mothers aged 25 years and above with $37.3 \%(n=999)$ mothers with three or more pregnancies in the 2015-2017 cohort. The majority $(62.6 \%)$ has had one or two pregnancies. In contrast only $56.5 \% \quad(n=2523)$ had one to two pregnancies in the 1983 cohort. Hence in the new millennium, a shift towards a small family norm was noted with younger mothers. The distribution of mothers according to parity is seen in Figure 2. 


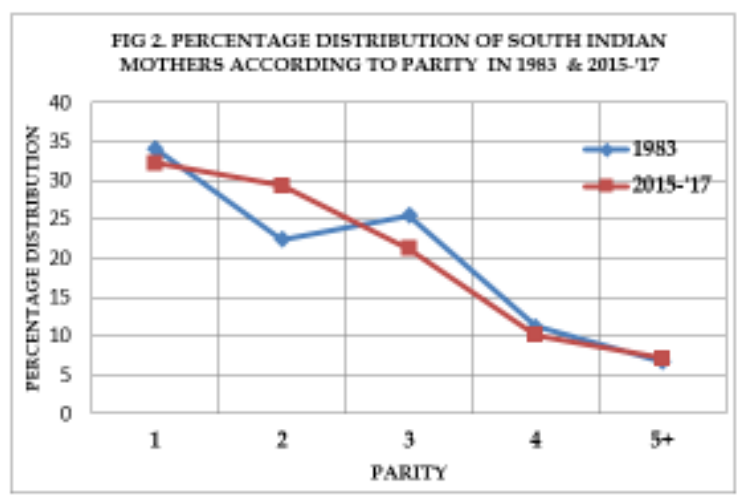

Newborns in the birthweight $2500-2999 \mathrm{~g}$ category peaked to $43.7 \%(n=1918)$ among 4381 births with known birthweight in the 1983 cohort compared to $38.1 \%(n=1032)$ among 2708 births with known birthweight in the 2015-2017 cohort, but with $80.9 \%$ $(\mathrm{n}=2191)$ babies weighing $2500 \mathrm{~g}$ and above in the recent 2015-2017 cohort compared to $71.6 \%$ $(n=3141)$ in the earlier 1983 cohort. Low birthweight below $2500 \mathrm{~g}$ in the 1983 cohort comprised $29.2 \%(\mathrm{n}=1309)$ compared to $19.1 \%(\mathrm{n}=$ 517 ) in the 2015-2017 cohort. Distribution of newborns by birthweight is seen in Figure 3.

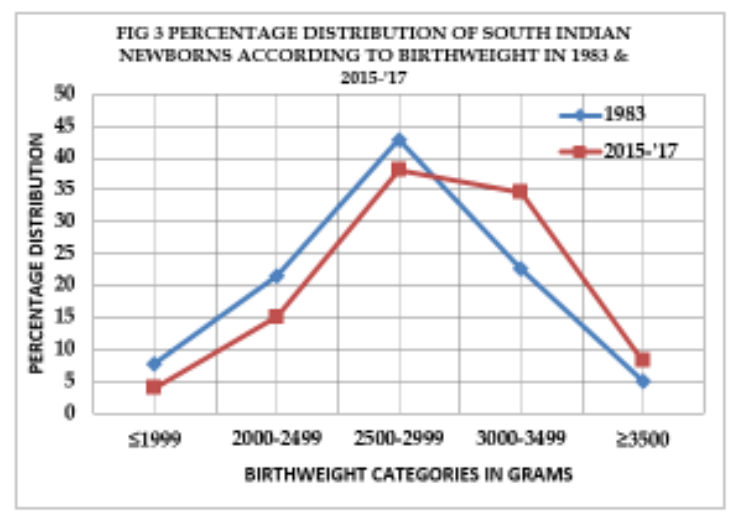

First birth infants comprised $32.7 \%(n=876)$ in the 2015-2017 cohort, while second and later births comprised $67.2 \%(n=1797)$, though $37.7 \%(n=1797)$ of later births weighed $3000-3499 \mathrm{~g}$, compared to $41.6 \%(n=876)$ first birth infants who weighed 2500 $2999 \mathrm{~g}$. The mean birth weight for first and later birth infants were $2817 \pm 484 \mathrm{~g}$ and $2899 \pm 503 \mathrm{~g}$ respectively, a difference of $82 \mathrm{~g}(p=0.0001)$. Thus, younger primigravida mothers tended to have smaller babies. However in the 2015-2017 cohort a minimal increase by $10.4 \%$ of birthweight $>2500 \mathrm{~g}$ was noted when compared to the 1983 cohort with older mothers having three or more pregnancies and heavier babies.

The mean gestation was 38.8 weeks in the 1983 cohort and 38.2 weeks in the 2015-2017 cohort. Term newborns $>37$ weeks comprised 92.9\% $(\mathrm{n}=4149)$ in the 1983 cohort and $88.3 \%(n=2243)$ in the 2015-2017 cohort. Prematurity ( $<37$ weeks) was
$7 \%(\mathrm{n}=315)$ in the 1983 cohort and $11.6 \%(\mathrm{n}=295)$ in the 2015-2017 cohort. There were no post term births beyond 42 weeks. Most $(45.6 \%, n=1893)$ term infants in 1983 cohort compared to $39 \%(n=875)$ in 2015-2017 cohort weighed 2500-2999g while preterm $34.2 \%(n=108)$ in 1983 cohort weighed $1500-1999 \mathrm{~g}$, and $36.6 \%(\mathrm{n}=108)$ preterm in 2015 2017 cohort weighed 2000-2499g.

Peak births in the two South Indian cohorts, 1983 (32.6\%) and 2015-2017 (28.1\%) occurred at $39^{\text {th }}$ and $38^{\text {th }}$ weeks of gestation respectively. In contrast, most ethnic Caucasian- British women went into spontaneous labour during the 41st and 42nd week of gestation ${ }^{5}$. The mean gestation $38.86 \pm 1.29$ (SD) and $38.2 \pm 2$ (SD) weeks in 1983 and 2015-2017 cohorts respectively, contrasted with peak births 31 percent at 41 weeks among 2100 Caucasian women with mean gestation of $41.03 \pm 1.32$ (SD) weeks, this difference being statistically significant $(p<0.001)$. In fact, less than $9 \%$ of Asian women gave birth at 40 completed weeks or 280 days gestation at the expected date of delivery (EDD). In fact more than 90\% Asian-Indian women gave birth before EDD. Thus a significant shortened gestation at birth was noted among the South Indian (Asian) population, differing by up to four weeks compared to Caucasian births. This shortened gestation at birth in ethnic Asians results in lower birthweight in the small Asian newborns. The percentage distribution of births by week of gestation from last menstrual period (LMP) in two ethnic Asian (Indian) 1983 and 2015-2017 cohorts and Caucasian (British) cohort is seen in Figure 4.

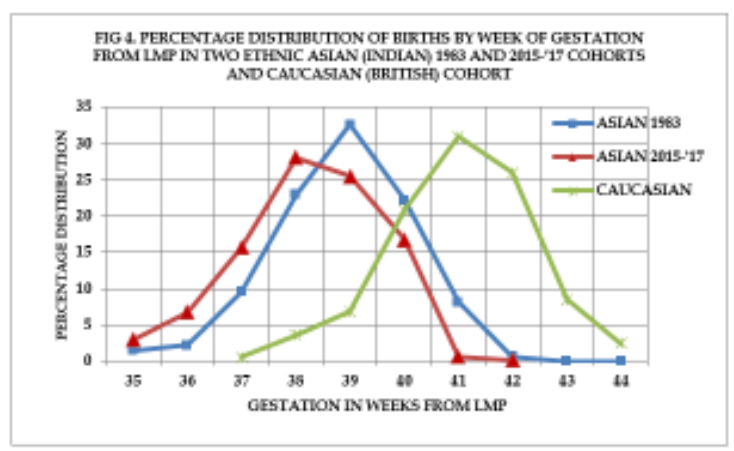

Comparison of birthweight and gestational age centiles in the 1983 cohort and 2015-2017 cohort revealed almost similar intrauterine growth curves, but between gestational ages of 32-37 weeks, birthweight centiles were higher by $100-300 \mathrm{~g}$ birthweight in the 2015-2017 cohort compared to 1983 cohort. Weight gains thereafter were almost similar in both cohorts between 38 to 39 weeks except that the $90^{\text {th }}$ percentile curve revealed 300 to $500 \mathrm{~g}$ higher birthweight in 1983 cohort at 40 weeks compared to 2015-2017 cohort which later peaked by $300 \mathrm{~g}$ at 41 weeks. Superimposition of the 1983 and 2015-2017 intrauterine growth charts for 
$10^{\text {th }}, 25^{\text {th }}, 50^{\text {th }}, 75^{\text {th }}$, and $90^{\text {th }}$ percentile curves is seen in Figure 5.

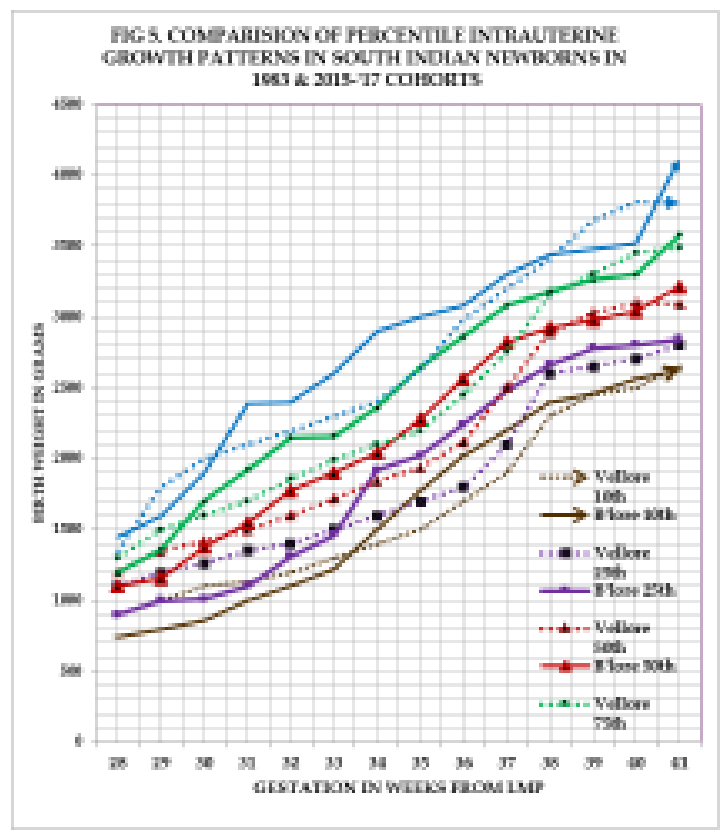

Superimposition with national and international $50^{\text {th }}$ percentile growth curves from North Indian ${ }^{6}$, Lubencho (Colorado) ${ }^{7}$ computed in 1960s and WHO reported in $2017^{8}$, revealed that both North and South Indian centiles were lower for all gestational ages compared to Lubchenco $50^{\text {th }}$ centile curve with up to $300-500 \mathrm{~g}$ for preterm 32-37 weeks gestation. Thereafter, Indian babies registered a 'catch up' growth but still lower by $100-300 \mathrm{~g}$ for term gestation $>38$ weeks. WHO $50^{\text {th }}$ centile curve corresponded closely to Lubchenco curve for preterm gestation $<37$ weeks but increased by $500 \mathrm{~g}$ at 40 weeks ${ }^{8}$. Superimposition of the $50^{\text {th }}$ percentile intrauterine growth curves for South Indian 1983 and 2015-2017 cohorts, study from North India, Colorado (Lubchenco) and multinational WHO percentile curve is seen in Figure 6.

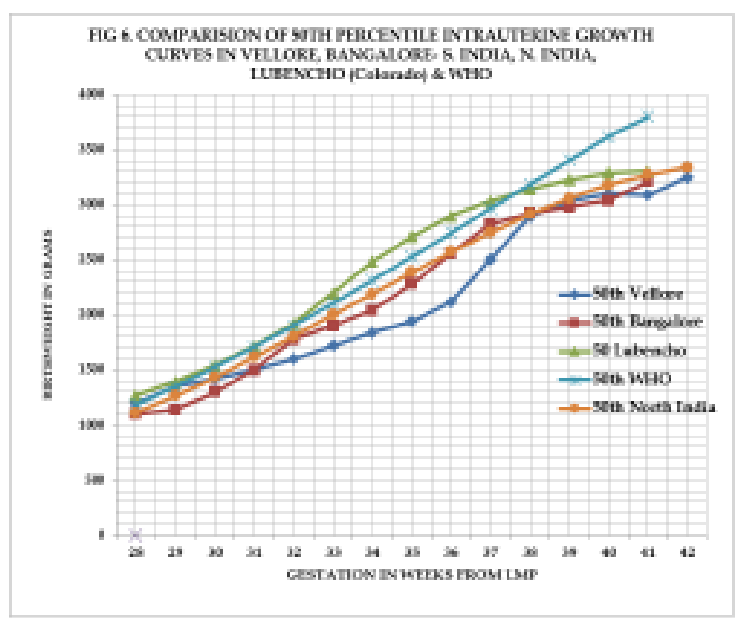

\section{Discussion}

Birthweight percentiles represent cross-sectional measurement of birthweight at birth. An increase in birthweights is to be expected in more recent studies due to technological advances and economic reforms over the decades. However, the mean birthweight in the 1983 cohort from Vellore (2881g) was similar three decades later $8 \mathrm{~g}$ less at $2873 \mathrm{~g}$, in 2015-2017 cohort from Bangalore, South India, both centres situated about $300 \mathrm{~km}$ apart, catering to almost similar middle and lower socioeconomic populations. Low birth weight (LBW) was $29.2 \%$ in the 1983 cohort and decreased to $19.1 \%$ in the 2015 2017 cohort. In the 2015-2017 cohort, very low birth weight (VLBW $<1500 \mathrm{~g}$ ) babies, comprising $1.6 \%$, had a mean gestation of $33.7 \pm 4.2$ weeks compared to LBW $(1500-2499 \mathrm{~g})$ infants with a mean gestation of $37.3 \pm 1.8$ weeks, this being statistically significant $(p<0.001)^{9-11}$.

Similarly, a study from North India reported a mean birth weight of $2725.40 \pm 424.64 \mathrm{~g}$, mean gestation of $38.1 \pm 1.9$ (SD) weeks and LBW of $19.8 \%$ in $2010^{12}$. Another study from South India reported a mean birthweight of 2846g in the year 1996 and $2907 \mathrm{~g}$ in 2010 (15 years later) a difference of 61 grams in the mean birthweights over one and a half decades ${ }^{13}$. In contrast, western populations report a high mean birth weight of $3446 \mathrm{~g}$ in U.S. born white women, a difference of $573 \mathrm{~g}$ compared to the 2015-2017 study $^{14}$. Thus, most Asian births occurred at 38-39 weeks or four weeks before peak Caucasian births at 41-42 weeks ${ }^{5}$. This shortened gestation at birth among Asian-Indian babies result in small babies with lower birthweight compared to Caucasian newborn with longer gestation up to 41-42 weeks who continue to gain weight.

Another interesting demographic trend in the new millennium is a shift towards a small family norm with changes in maternal factors of age and parity with young primigravida. In the 2015-2017 study cohort $32.7 \%(n=876)$ primigravida mothers showed a progressive decline by $5-10 \%$ for subsequent pregnancies compared to $34.1 \%$ primigravida mothers, $22.4 \%$ second gravida mothers, increasing to $25.5 \%(n=1134)$ third gravida mothers in 1983 cohort. Thus, two thirds (62.6\%) of women had one to two pregnancies in the 2015-2017 cohort compared to half $56.5 \%$ in the 1983 cohort.

Younger mothers aged 20-24 years peaked at $40 \%$ $(\mathrm{n}=1012)$ in $2015-2017$ cohort compared to $16 \%$ $(n=553)$ in the 1983 cohort, a difference of $24 \%$. Thus $70.9 \%$ in 1983 cohort were older, above 25 years compared to $52.2 \%$ in $2015-2017$ cohort. Also $32.7 \%$ primigravida mothers delivered babies with mean birth weight of $2817 \pm 484 \mathrm{~g}$ compared to $67.2 \%$ second and more births with mean birth weight of $2899 \pm 503 \mathrm{~g}$, which is a significant $(p=0.0001)$ 
difference of $82 \mathrm{~g}$. Thus, younger primigravida mothers tended to have smaller babies in the 20152017 cohort.

Comparison of Asian-Indian intrauterine growth curves constructed in 1983 and 2015-2017 cohorts demonstrates an inherent genetic predisposition rather than influence of environmental factors of improved obstetric care, technological advances with economic reforms, in that growth patterns for $10^{\text {th }}, 25^{\text {th }}, 50^{\text {th }}, 75^{\text {th }}$, and $90^{\text {th }}$ centiles in 1983 and 2015-2017 cohorts was similar up to 32 weeks, diverging by 100-300g increase in 2015-2017 cohort to 37 weeks, following which there was catch-up increase weight in 1983 cohort till 40-42 weeks; however, $90^{\text {th }}$ centile in $2015-2017$ cohort revealed $500 \mathrm{~g}$ increased weight at 40-41weeks.

National and international comparison of mean, $50^{\text {th }}$ percentile growth curve for present study in 1983 and 2015-2017 cohort from South India and North India among 2875 consecutive live born babies' percentile curves which were not significantly different in comparison to past growth curves made 2 decades back from the same centre ${ }^{6,15}$ being lower up to $600 \mathrm{~g}$ for preterm gestation compared to Lubecheno's ${ }^{5}$ computed in 1960s but with catch up at term. Multinational WHO charts show a rapid weight gain of $500 \mathrm{~g}$ in term gestation after 38 weeks, and though recommended for international use, are not appropriate and ethnic specific. Asian charts are needed for local use to increase diagnostic and predictive performance ${ }^{8}$. Normal fetal growth occurs most rapidly from 12-36 gestational weeks. Fetal growth rate peaks to $220-225 \mathrm{~g} /$ week at $32-36$ gestational weeks and declines subsequently ${ }^{16}$. This study demonstrated relatively high rates of preterm births in the 2 South Indian cohorts and shortened gestation resulted in high rates of LBW. Thus, different guidelines are required for Asian-Indian newborns due to inherent factors of poor fetal growth as well as significantly shorter pregnancy duration $^{17}$.

SGA rates are determined using the $10^{\text {th }}$ percentile cut-off on the fetal growth standard. Most units in India use Lubchenco charts to classify newborns as SGA and LGA. However, birthweights for South Indian babies were lower across all gestations in comparison with that of Lubchenco, $50^{\text {th }}$ percentile, though a North Indian study reported higher birthweights only for term gestation above 38 weeks. Thus, if population specific updated growth charts are not used for categorisation of infants as SGA, LGA or AGA, there will be an overestimation of the frequency of SGA babies and an underestimation of the frequency of LGA babies.

The importance of these centile growth curves in a South Indian cohort of singleton live births brings to the forefront, unique ethnic differences in intrauterine growth patterns when compared to the Caucasian counterparts where notable differences are observed. Regional ethnic specific intrauterine growth charts have potential implications for use in clinical practice, as implementation of these new charts offers more accurate identification of the cohort of SGA babies with intrauterine growth retardation who require increased monitoring and observation, special care, additional feeding and who are at risk of a poor outcome. Asian-Indian babies require different guidelines for their wellbeing as opposed to Caucasian newborns with guidelines stated in all text books well adapted to the West or even multinational WHO intrauterine growth curves.

\section{Conclusions}

The 2015-2017 centile charts for birthweight in babies born from 28 to 42 gestational weeks in the metropolitan city of Bangalore, South India had almost similar growth curves and mean birthweights compared to the 1983 South Indian centile chart indicating an inherent genetic predisposition for the small Indian baby. The updated centiles for births during 2015-2017 provide a more valid tool to assess South Indian fetal growth.

\section{References}

1. Wilcox A, Skjaeven R, Buekens P, Kiely J. Birthweight and perinatal mortality. A comparison of the United States and Norway. Journal of the American Medical Association 1995; 273: 709-11. https://doi.org/10.1001/jama.1995.035203 30039034

PMid: 7853628

2. Stein ZA, Susser M. Intrauterine growth retardation: epidemiological issues and public health significance. Seminars in Perinatology 1984; 8: 5-14.

PMid: 6710174

3. Berkowitz GS, Papiernik E. Epidemiology of preterm birth. Epidemiologic Reviews 1993; 15: 414-3.

https://doi.org/10.1093/oxfordjournals.epir ev.a036128

4. Arnold CC, Kramer MS, Hobbs CA, et al. Very low birthweight: a problematic cohort for epidemiological studies of very small or immature neonates. American Journal of Epidemiology 1991; 134: 604-13. https://doi.org/10.1093/oxfordjournals.aje. a116133

PMid: 1951265 
5. Park GL: The duration of pregnancy. Lancet 1968; ii: 1388. https://doi.org/10.1016/S01406736(68)92685-8

6. Mohan M, Chellani H, Prasad SR, Kapani $\mathrm{V}$. Intrauterine growth curves in north Indian babies: weight, length, head circumference and ponderal index. Indian Pediatrics 1990: 27(1); 43-51.

PMid: 2361742

7. Lubchenco LO, Hansman C, Dressler M, Boyd E. Intrauterine growth as estimated from live born birthweight data at 24 to 42 weeks of gestation. Pediatrics 1963:32; 793-800.

PMid: 14075621

8. Kiserud T, Piaggio G, Carroli G, Widmer M, Carvalho J, Jensen LN, et al. The World Health Organization Fetal Growth Charts: A multinational longitudinal study of ultrasound biometric measurements and estimated fetal weight. PLOS Medicine. Published: January 24, 2017 https://doi.org/10.1371/journal.pmed.1002 220

9. Jadhav M, Christopher GL. Perinatal mortality rates in Vellore, Part I. A study of 21,585 infants. Indian Journal of Pediatrics 1986: 53; 351-3. https://doi.org/10.1007/BF02760413

10. Christopher GL, Jadhav M. Perinatal mortality in Vellore Part II. Lethal malformations. Indian Journal of Pediatrics 1986: 53; 353-7. https://doi.org/10.1007/BF02760414 PMid: 3759212

11. Christopher GL. The effect of biological factors on birthweight and gestation in South Indian newborns. Journal of Pediatric Neurology and Medicine 2018; 3(1): 97-103. https://doi.org/10.4172/2472100X.100013 0
12. Kumar A, Chaudhary K, Prasad S. Maternal indicators and obstetric outcome in North India. A hospital-based study. Journal of Postgraduate Medicine 2010: 56(3); 192-5.

https://doi.org/10.4103/0022-3859.68647

PMid: 20739764

13. Kumar VS, Jeyaseelan L, Sebastian T, Regi A, Mathew J, Jose R. New birth weight reference standards customized to birth order and sex of babies from South India. BMC Pregnancy Childbirth 2013; 13:38. https://doi.org/10.1186/1471-2393-13-38 PMid: 23409828 PMCid: PMC3583685

14. David RJ, Collins JW Jr. Differing birth weight among infants of U.S.-born blacks, African-born blacks and U.S.-born whites. New England Journal of Medicine 1997; 337(17): 1209-17.

https://doi.org/10.1056/NEJM1997102333 71706

PMid: 9337381

15. Ghosh S, Bhargava SK, Madhavan S, Taskar AD, Bhargava V, Nigam SK. Intra-uterine growth of North Indian babies. Pediatrics 1971; 47(5): 826-30. PMid: 5573867

16. Metcoff J. Maternal fetal nutritional relationships. In Arneil GC, Metcoff J, editors: Pediatric Nutrition. London: Butterworth; 1985. pp 56-106 PMid: 3993611

17. Christopher GL. Low birth weight criteria in ethnic Asian, Eurasian and Caucasian newborns. Recent advances in perinatology with specific reference to ethnicity. $2^{\text {nd }}$ Edition, Published by Dr. Grace Lalana Publications: 2018, Chapter 29; 253-257. https://www.newgenparenting.com 